\title{
PVSITES: Building-Integrated Photovoltaic Technologies and Systems for Large-Scale Market Deployment ${ }^{\dagger}$
}

\author{
Juan Manuel Espeche ${ }^{1, *}$, Federico Noris ${ }^{1}$, Zia Lennard ${ }^{1}$, Simon Challet ${ }^{2}$ and Maider Machado ${ }^{3}$ \\ 1 R2M Solution, srl., Via Fratelli Cuzio 42, 27100 Pavia, Italy; \\ federico.noris@r2msolution.com (F.N.); Zia.Lennard@R2Msolution.com (Z.L.) \\ 2 WIP Renewable Energies, Sylvensteinstr 2, 81369 Munich, Germany; simon.challet@wip-munich.de \\ 3 Tecnalia, Parque Cientifico y Tecnologico de Gipuzkoa Mikeletegi Pasealekua 2, \\ E-20009 Donostia-San Sebastian, Spain; maider.machado@tecnalia.com \\ * Correspondence: juan.espeche@r2msolution.com; Tel.: +39-382-172-6596 \\ † Presented at the Sustainable Places 2017 (SP2017) Conference, Middlesbrough, UK, 28-30 June 2017. \\ Published: 3 November 2017
}

\begin{abstract}
The large potential for energy savings in buildings led the EU Commission to adopt the 2010/31/EU Directive on the energy performance of buildings with the objective that all new buildings are Nearly Zero Energy Buildings (NZEB) by 2020. Renewable energy technologies, and in particular the integration of photovoltaic systems in the building environment offer many possibilities to play a key role within the NZEB scenario. The objective of PVSITES project is to drive BIPV technology to a large market deployment by demonstrating an ambitious portfolio of building-integrated solar technologies and systems, giving a forceful, reliable answer to the market requirements identified by the industrial members of the consortium in their day-to-day activity.
\end{abstract}

Keywords: building-integrated PV; nearly zero energy buildings; renewable energy technologies

\section{Introduction}

Building-integrated photovoltaics (BIPV) is currently an expansive market. Market analysts estimate a compound annual growth rate of $18.7 \%$ and a total of $5.4 \mathrm{GW}$ installed worldwide between 2013 and 2019. One of the main drivers for BIPV market growth in the EU is the increasingly demanding legislation related to energy performance in buildings. Despite this favorable framework for BIPV technology market uptake, initial estimations of BIPV market growth have been subsequently overestimated in the past few years. A series of demands from the stakeholders which have not been properly addressed by the BIPV value chain are the cause for this deviation. These key requirements are mainly related to the flexibility in design and aesthetics considerations, lack of tools integrating PV and building performance, demonstration of long-term reliability of the technology, compliance with legal regulations, smart interaction with the grid and cost effectiveness. BIPV technology market uptake has been hindered in the past years by the difficulties of the industry in providing holistic solutions complying with the key demands from decision makers and end-users. PVSITES has been conceived as an industrial joint approach to provide robust BIPV technology solutions to comply with these needs. The ultimate goal is to significantly enhance BIPV market deployment in the short and medium term. 


\section{Challenges and Solutions}

\subsection{Design}

The challenge of enhanced flexibility of design, outstanding aesthetical value and increased performance can be solved with a wide portfolio of BIPV products based on crystalline silicon and CIGS photovoltaic technologies complying with market requests. Every analysis on the current BIPV market situation shows that there are a series of demands from the stakeholders which have not been properly addressed by the BIPV industry. At module level, these key requirements are mainly related to the flexibility in design and aesthetics considerations, the demonstration of long-term reliability of the technology, compliance with legal regulations and cost effectiveness.

In order to fulfill the aforementioned critical aspects, different technical approaches and actions will be taken within PVSITES. With a basis on crystalline silicon and CIGS photovoltaic technologies, a large portfolio of products will be generated, attending to former market demands. Glazed skylight and façade systems will include glass-glass back contact c-Si cell technology, XL format and large thickness BIPV modules, fully opaque façades with hidden busbars and L-interconnections and curved glazing with integrated flexible CIGS, all manufactured by Onyx Solar, with performances up to $160 \mathrm{~W} / \mathrm{m}^{2}$. Flisom will demonstrate a portfolio of products based on a new lightweight, flexible, roll-to-roll monolithically connected CIGS solar modules on polymer films: solar roof tiles and façade elements with 10-14\% module efficiency integrated on metal sheets using cost effective materials and processes; large area BIPV elements on metal sheets for integration in roofs and façades and bendable elements for flexible roofing.

The early design stages of a BIPV installations will be supported with the development of a software tool for the joint simulation of BIPV products and building energy performance. An accurate, user-friendly, integrated software tool for performance prediction of BIPV (and also building adapted) products and their impact on building energy performance will be thus developed. The projected tool will be unique in the market, offering an integrated PV-building approach, providing updated information on legislation compliance, and setting a simplified framework for architects and thermal engineers to share information on the building project from different levels of software complexity, adapted to their needs. All along this work chain, PV, BIPV and construction products manufacturers are also involved through product libraries containing all the technical information needed for the design process.

\subsection{Multifunctionality}

Fostering synergies between multifunctional BIPV systems and other functional building elements can be achieved with low concentration and passive solar control BIPV systems. Although space heating is still the dominant energy demand for buildings in most European countries, special attention should be paid to space cooling, since the energy consumption it accounts for (mostly electric energy) is growing rapidly as a consequence of global warming. Architectural integration of the BIPV systems proposed tackles this issue by fostering passive synergies with the thermal building envelope. A low concentration photovoltaic solution with associated passive climate control for building integration in façades and skylights will be demonstrated in this project. Semitransparent glass-glass crystalline silicon PV modules in conjunction with integrated optical elements (Fresnel lenses) are proposed. The optical system, with no mechanical parts, is designed to concentrate solar radiation onto the cells during the central part of the year and allow light passing towards the interior of the building during the winter.

\subsection{Grid Integration}

The need for a solar BIPV generation more predictable, manageable, grid-friendly and profitable in terms of building energy savings is being addressed in PVSITES project by combining a flexible and high efficiency grid interface for BIPV systems and new building energy management strategies will be developed. The main drawback of PV energy is its dependence on variable solar resource 
impacting on grid operation. Potential countermeasures are well-known: improvement of solar PV energy short-term forecast, demand response methods and utilization of energy storage. However, these techniques mean significant external costs reducing PV competitiveness and, consequently, they are still far from being worthwhile.

\section{Demonstration}

The need to demonstrate reliability of advanced BIPV solutions by effective incorporation onto real buildings takes form in the PVSITES project through high impact demonstrations in real buildings and experimental facilities throughout Europe. The progressive acceptance of BIPV installations require advanced showrooms with a high visibility towards involved stakeholders and the general public. Advanced training activities should be offered to foster the integration of BIPV in building works. In PVSITES, the proposed module, grid interface and energy management technologies will be demonstrated in 7 installations covering different EU electricity markets and climates, building uses (residential, industrial, commercial), new buildings and retrofitting, public and private property, and different architectural implementations. This diversity will provide the largest potential for replication. The table below provides an overview of the demo cases (Figure 1).

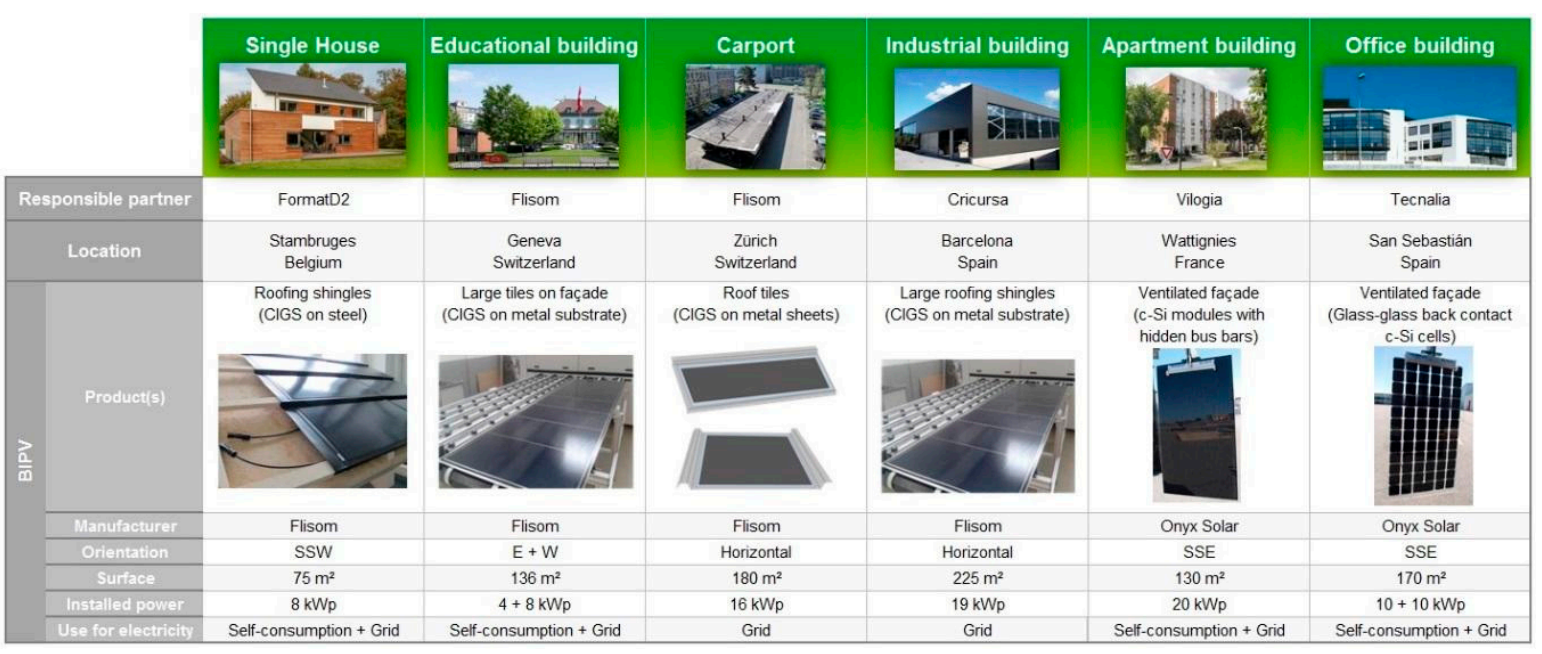

Figure 1. PVSITES demo cases.

\section{Impact}

Building-integrated photovoltaics (BIPV) is an expansive market, with estimated cumulative installations around $343 \mathrm{MW}$ in 2012, it is expected to reach $1152 \mathrm{MW}$ in 2019, growing at a Compound Annual Growth Rate (CAGR) of 18.7\% from 2013 to 2019 [1]. In 2012, the EU led the BIPV market, with $41 \%$ of total installations, followed by USA with $27 \%$. Currently, the evident market growth shown by countries that support BIPV through an encouraging legislation (e.g., France, Switzerland) and the increasingly demanding legislation related to energy performance in buildings in the EU depict a promising future for the sector.

Despite this favorable framework, it is a fact that estimations of BIPV market growth have been subsequently overestimated in the past few years. A series of primary demands from the stakeholders which have not been properly addressed by the BIPV value chain are the main cause for this deviation. These key requirements are mainly related to the flexibility in design and aesthetics considerations, lack of tools integrating PV and building performance, demonstration of long-term reliability of the technology, compliance with legal regulations, smart interaction with the grid and, of course, cost effectiveness.

Under this market scenario, PVSITES aims at fostering BIPV technology market uptake by fulfilling the most relevant demands from stakeholders, mainly related to: aesthetics, flexibility in design, cost-effectiveness, high performance, reliability and compliance with standards. This will be 
achieved by demonstrating an ambitious portfolio of BIPV systems, tailored to provide a robust answer to market request.

\section{Conclusion}

During the expected duration of project activities ending in June 2019, PVSITES aims at fostering BIPV technology market uptake by fulfilling the most relevant demands from stakeholders. This will be achieved by demonstrating an ambitious portfolio of BIPV systems. The expected impacts are classified in several categories depending on what is concerned:

- Market impacts, through a $12.7 \%$ increase in total BIPV installed capacity in the period 20202024 with a payback time of 5-7 years at maximum.

- Increased competitiveness of EU industry with an associated job creation between 37,900-39,651 direct + indirect jobs in the BIPV sector in 5 years.

- Environmental impacts from additional $1263 \mathrm{MW}$ installed power due to PVSITES from 2020 to 2024 , with a reduction of overall $\mathrm{CO}_{2}$ emissions $12.7 \%$ higher than business as usual case.

- Smart management of the building energy demand and the electricity injection into the grid, thus reducing the potential grid stress and the need to reinforce the grid.

- Increased stakeholder awareness and acceptance of BIPV as a consequence of high impact demonstration and targeted dissemination actions.

Acknowledgments: This project has received funding from the European Union's Horizon 2020 research and innovation programme under grant agreement No 691768. The project can be referenced at http://www.pvsites.eu/.

Author Contributions: The sections were adopted from the grant proposal by Juan Manuel Espeche, Federico Noris, Simon Challet, and Maider Machado. The paper was compiled, edited, and reviewed by Zia Lennard.

Conflicts of Interest: The authors declare no conflict of interest.

\section{References}

1. Building Integrated Photovoltaics (BIPV) Market. Global Industry Analysis, Size, Share, Growth, Trends and Forecast, 2013-2019. Transpar. Mark. Res. 2014.

(C) 2017 by the authors. Licensee MDPI, Basel, Switzerland. This article is an open access article distributed under the terms and conditions of the Creative Commons Attribution (CC BY) license (http://creativecommons.org/licenses/by/4.0/). 